\title{
VARIATIONS IN METADISCOURSE USE IN ENGLISH LANGUAGE INTRODUCTION AND LITERATURE REVIEW THESIS CHAPTERS
}

\author{
Osei Yaw Akoto ${ }^{1}$, Joseph Benjamin A. Afful ${ }^{2}$ \\ ${ }^{1}$ Kwame Nkrumah University of Science and Technology, Kumasi, Ghana, \\ ${ }^{2}$ University of Cape Coast, Cape Coast, Ghana \\ E-mail: oseiyaw.akoto@yahoo.com
}

Received: 24 June 2020

Accepted: 10 December 2020

\begin{abstract}
Studies have established that thesis chapters are both similar and dissimilar with respect to their rhetorical choices. This paper examined metadiscourse use in the Introduction and Literature Review (LR) chapters of English Language theses from a nonnative context. The Introduction and LR chapters of ten theses, resulting in 50, 000 and 100, 500 words respectively, constituted the data sets for this study. Drawing on Hyland's metadiscourse model, we manually coded all the metadiscursive elements. The study reveals statistically significant differences across all the interactive and interactional subcategories, affirming the stance that the rhetorical function of a thesis chapter influences its metadiscoursal choices. The study also found a new subcategory of meta-discoursal category labeled continuants. The paper has implications for the teaching and supervision of postgraduate theses, and the theory of metadiscourse.
\end{abstract}

Keywords: continuants, master's thesis, metadiscourse, disciplinary variation, thesis chapters.

\section{Introduction}

Interaction-in-writing has engendered the attention of discourse analysts, applied linguists, and corpus linguists for years. It is established that writer-reader interaction in writing, specifically, academic writing is influenced by disciplinary norms, values and conventions (Ädel, 2006; Hyland, 2004, 2005). Hyland (2004), therefore, uses the expression disciplinary interactions to denote writer-reader associations sanctioned and conditioned by disciplinarity. Metadiscourse constitutes one of the various resources employed to realize interaction in text. It encompasses rhetorical resources that are deployed to achieve textual interaction between writers and readers (Adel, 2006; Hyland, 2005). Metadiscoursal resources generally help in the organization of the proposition, and management of the relationship between discourse participants (i.e. writers and readers) (Ädel, 2005, 2006; Burneikaitè, 2008, 2009a, b, c). Williams (2010) argues, therefore, that a discourse is not a monologue but an 'internalized dialogue' (p. 10).

Several studies (Akoto, 2019, 2020; Hyland \& Tse, 2004; Hyland, 2004; Burneikaitè, 2008, 2009a, b \& c; Musa, 2014a, b; Yoon \& Römer, 2020) have investigated the extent to which disciplinarity influences the employment of metadiscourse in postgraduate writings in general and master's thesis in particular. These studies have established differences and similarities in metadiscourse use. The differences although can be informed by individual idiosyncrasies, 
institutional differences, geopolitical factors, and socio-cultural factors (Abdollahzadeh, 2011; Burneikaitè, 2008), several studies (Akoto, 2019, 2020; Musa, 2014a, b) attributed their realized variations to differences in disciplinary values, norms and conventions. For example, Hyland (2004) found that metadiscoursal resources were more frequent in Applied Linguistics master's theses than in Public Administration, Business Studies, Computer Science, Electronic Engineering and Biology. On the other hand, generalities in metadiscourse use in master's theses across disciplines are also ascribed to genre-based (genre-part-based) factors such as communicative functions, positioning and generic requirements (Akoto, 2019, 2020; Hyland, 2004). For example, studies (Hyland, 2005; Burneikaite, 2008, 2009a, b, c; Musa, 2014a, b) have discovered that both interactional and interactive metadiscourse devices are commonplace rhetorical devices in master theses.

Studies on metadiscourse use in master's thesis either adopt the lumping (Can \& Yuvayapan, 2018) or splitting approach (Ädel, 2010), whereby the complete thesis (from Chapter 1 to the last) constitutes the corpus, or a Chapter of the thesis constitutes the data set respectively. The splitting approach, which is microscopic in nature (Akoto, 2019, 2020; Yu, 2016), seeks to reveal chapterological variation with respect to metadiscourse use. Scholars on metadiscourse engage in chapterology to ascertain the extent to which differences in communicative functions and placement of thesis chapters influence metadiscourse use. Consequently, some researchers have undertaken intra-disciplinary studies on different chapters (Akoto, 2019, 2020; Duruk, 2017; Haufiku \& Kangira, 2018; Zahra, Roya \& Shahla, 2015). These studies generally concluded that metadiscourse use is chapter-specific, affirming Ädel's (2006: 188) assertion that 'some types of metadiscourse tend to occur at specific points in texts".

In spite of the plethora of metadiscourse studies on thesis chapters (Akoto, 2019; 2020; Duruk, 2017; Yu, 2016), the Introduction and Literature Review chapters in English Language theses have not been investigated. Drawing on interactive and interactional categories in Hyland's (2005) model of metadiscourse, this paper examines metadiscourse use across the Introduction and Literature Review (LR) chapters in English Language discipline to ascertain intra-disciplinary variation, which bothers on inter-chapter variations, to deepen our understanding on "dissertation chapter's heterogeneity" (Olmos-Lopez, 2015: 51). Regarding the disciplinary profile of English Language, Becher (1989) describes it as a soft science; Biglan (1973) classifies it as soft-pure-non-life discipline while Hyland (2009) features it as part of humanities.

The rest of the paper is organized as follows. The concept of metadiscourse is first examined. Then, it proceeds to discuss the methodological choices made in the study. This is followed by the analysis, and discussion of results. The paper is concluded with implications of the findings and recommendation for further research.

\section{Literature Review}

\subsection{Metadiscourse}

Within the past two decades, authors from various theoretical backgrounds have theorized the concept metadiscourse. These attempts have resulted in numerous definitions and categorizations. A common theme in the various theories is that writing involves writerreader interaction. This theme is explicitly or implicitly revealed in the definitions of metadiscourse by scholars such as Vande Kopple (1985), Crismore et al (1993), Hyland ( 2005, 2017), Ädel (2006)and Burneikaitè (2008). These scholars believe that academic communication means a lot more than the ideational material. They consider metadiscourse 
as a useful part of a text, contributing to text structuring and interaction between a writer and his/her audience.

The theoretical attention has resulted in a proliferation of theories on the phenomenon. These include Systemic Functional Grammar (SFG)-inspired models (Vande Kopple 1985; Crismore et al., 1993; Hyland, 2004, 2005), speech act-related theory (Beauvais, 1989), Jacobson-based theory (Ädel, 2006), relevance theory (Aguilar, 2008), and cooperative principle-based theory (Abdi, Rizi \& Tavakoli, 2009). All these theories consider academic writing as a social activity which involves writer-reader interaction, in conformity to a particular discourse community. Abdi et al (2009), therefore, acknowledged:

All of the models, in one way or another, are recognitions of a belief that the use of language for communication is not just an attempt to transfer information and knowledge; rather it is also normally accompanied by cooperative efforts like organization, evaluations, feelings, engagement... (p. 5)

Among the various theoretical perspectives on metadiscourse, the one that has received a general attention is the SFG-based. The reason may be due to the fact that metadiscourse itself is a functional category (Hyland, 2004, 2005; Tse \& Hyland, 2004). All the SFG-based theories, except Hyland (2004), distinguish between the 'ideational discourse' and 'textualinterpersonal discourse' (which is the focus of metadiscourse). However, Hyland (2004) argued that metadiscourse relates to only the interpersonal resources, implying that any linguistic element which is metadiscoursal is also an interpersonal resource. This characteristic of Hyland's model distinguishes it from all the other models on metadiscourse.

Hyland's (2005) model of metadiscourse forms the theoreticalthrust ((as well as the analytical framework) of this study. Hyland (2005)describes metadiscourse as 'an umbrella term used to include an apparently heterogeneous array of cohesive and interpersonal features which help relate a text to its context' (p. 16). This stance on metadiscourse is premised on the interpersonal metafunction of language in systemic functional grammar. Hyland's model of metadiscourse considers language as a system of interactive resources used for mainly interpersonal purposes. Consequently, Hyland (2005), in identifying linguistic resources that have metadiscoursal potentials, does not pose the question 'what is the function of the item' but rather 'what is this item doing here at this point in time in the text' or 'here and now', as Gee (1999) puts it. Within Hyland's (2005) framework of metadiscourse, the concept metadiscourse is considered as a linguistic, pragmatic and rhetorical phenomenon. Writers, therefore, use metadiscoursal resources to 'discourse about discourse' for a rhetorical purpose and also establish rapport with the participants in the discourse internal world (Hyland, 2004; Tse \& Hyland, 2004, 2005). Metadiscourse is, therefore, seen as a medium through which interpersonal relation, in a text, is established, thereby perceiving a writer and the anticipated reader as people in a social world (Hyland, 2005). Hyland (2005) provided three key parameters in identifying metadiscourse:

Metadiscourse is distinct from propositional aspects of discourse.

Metadiscourse relates to aspects of the text that relate to writer-reader interaction.

Metadiscourse refers to relations only that are internal to the discourse (Hyland, 2005:159). 
Variations in Metadiscourse Use in English Language Introduction and Literature Review Thesis Chapters, Osei Yaw Akoto, Joseph Benjamin A. Afful

Guided by these three key principles, Hyland (2005) divided metadiscourse into two major categories: interactive and interactional.

\subsubsection{Interactive Metadiscourse Resources}

This category of metadiscourse concerns how textual resources are deployed in the management and organization of propositional/ideational information in texts. Writers use the interactive resources to convey their preferred interpretation to the anticipated readership of the discourse -be it spoken, written, visual or multimodal (Kumpf, 2000; Hyland, 2004, 2005; Aguilar, 2005). Tse and Hyland (2006: 770) argue that interactive resources 'are concerned with ways of organizing discourse to anticipate readers' knowledge and reflect the writers assessment of the readers' processing abilities, background resources, and intertextual experiences in order to decide what needs to be made explicit to constrain and guide what can be recovered from the text.' Hyland (2005) classifies interactive resources into five subcategories, which are discussed below.

Evidentials are the interactive resources used to show the source of propositional information in a discourse. They show references to "community-based literature and provide supports for arguments" (Hyland, 2005: 51). Examples of evidentials are 'According to J', 'They state', 'In their opinion', etc. These metadiscoursal resources reveal the authorities cited in a discourse thereby indicating to the readers the source or the origin of the writer's proposition.

Frame markers refer to the discourse acts, sequencers, or text stages or boundaries of schematic text structures. They make references to text boundaries or elements of text structure; to label text stages; to announce discourse goals, and to indicate topic shifts. In short, frame markers, according to Hyland (2005), provide framing information about the ideational materials of the discourse. Examples include, 'Finally', 'To sum up', 'Our focus is to', 'First', '1, 2, 3...', 'a, b, c...'.

Endophoric markers (or endophorics) are interactive resources which are used to make cataphoric and anaphoric references to other parts of an on-going discourse. Thus, they refer to earlier materials or propositions yet to be made in a discourse. Some examples are: 'In chapter one', 'Refer to table 2 below', 'The next section', etc.

Code glosses signal the reformulation, restatement or exemplification of ideational information. They help readers to grasp the detailed meanings of propositional information, especially when unfamiliar or technical expressions are used in a discourse. Consequently, Crismore and Farnsworth (1989) argued that code glosses 'function in the semantic system of language' (p. 98) use in texts to help make meanings clear to readers. Examples of code glosses include: 'In other words', 'Such as', 'For example', 'This means that', etc. Code glosses are sometimes marked off by parentheses and commas.

Transitions markers are the interactive resources that writers use to link their arguments to make them coherent and cohesive. They signal additive, causative, contrastive, and consequential steps in a discourse. They express semantic relations among main clauses in texts. They include conjunctions (e.g. and, however, and...), adverbials (e.g. similarly, sometimes, whenever...), and the likes.

\subsubsection{Interactional Metadiscourse Resources}

Interactional resources are used to create appropriate reader-sensitive atmosphere, and writer-reader relationship in discourse. They focus on participants of the interaction and seek to display the writer's persona and a tenor consistent with the norms of the disciplinary community' (Hyland, 2005: 50). Burneikaitè (2008) refers to interactional resources as 
participant-oriented metadiscourse. Interactional resources, therefore, focus on rapport establishment and management; and also attitude demonstration towards the proposition in a discourse. Heng and Tan (2010) noted that they relate to the socio-affective level where writer-reader engagement is given much prominence in discourse. Hyland (2005) subclassifies interactional resources into five, and these are discussed below.

Hedges, which include 'about', 'perhaps', 'to some extent', and 'may', are the interactional devices which indicate writers' reluctance to presentpropositional information categorically. They, therefore, withhold writers' full commitment and help writers to present facts as opinions and most importantly present academic discourse as 'the domain not of closed-fisted logic, but of open-handed rhetoric' (Crismore \& Fransworth, 1989: 95).

Engagement markers are the resources used by writers to register their readers in a discourse. Engagement markers create reader-sensitive environment, thereby revealing the writers' awareness of the anticipated readers. In effect, 'they explicitly address readers either by selectively focusing their attention or by including them as participants in the text through second person pronouns, imperatives, question forms, and asides'(Hyland, 2004: 139). Specific examples are imperatives/directives (e.g. 'Note that', 'See Page 4'; interrogatives (e.g. 'Do you agree to this?', 'Is it true?', and pronouns (e.g. you, your and inclusive we).

Attitude markers show the writer's appraisal or judgement of an ideational content. They indicate the writer's affective rather than epistemic attitude to proposition (Hyland, 2005). Attitudes are expressed by the use of subordination, comparatives, progressive particles and punctuations. Specific examples are 'most strikingly', 'unfortunately', 'I find it worthwhile that', etc.

Boosters are regarded as counter-hedging metadiscourse devices because, unlike hedges, they declare writers' certainty and absolute confidence in a proposition made in a discourse. Hyland (2005: 53) notes that 'boosters suggest that the writer potentially presents diverse positions but has chosen to narrow this diversity rather than enlarge it, confronting alternatives with a single confident voice'. Boosters include 'clearly', 'it is true that', and 'definitely.

Self mentions signal the projection and representation of a writer in a text. Through these, writers construct 'contextually situated authorial identity'. Hence, Blagojevic (2004) refers to it as author's presence. Examples are 'l', 'exclusive we', 'me', 'mine' and 'our/ours'.

The literature on metadiscourse implicitly reveals three approaches to categorizing metadiscoursal markers. These approaches are form-based (Crismore, 1984), function-based (Vande Kopple, 1985) and form-function-based (Ädel, 2005; Burneikaitè, 2008; Hyland, 2005) approaches. Out of these theoretical approaches, the form-function-based is considered the more elegant because it acknowledges the fact that different linguistic structures may perform the same metadiscoursal function and a particular structure can be both metadiscoursal and non-metadiscoursal, depending on the context within which it is found. However, among even the form-function-based theoretical perspectives on metadiscourse, Hyland's (2005) interpersonal model of metadiscourse is deemed the most appropriate because it 'builds on previous frameworks to offer a more theoretically robust and empirically grounded classification, representing a major reconceptualization of metadiscourse theory' (Tse \& Hyland, 2006: 768). This makes it the most comprehensive approach to metadiscourse study (Heng \&Tan, 2010).

Again, the focus (i.e. master's thesis) of the present study also influenced the choice of the model of metadiscourse. Hyland's model is considered the one that is appropriate to studies within academic discourse particularly genres like master's and postgraduate theses 
Variations in Metadiscourse Use in English Language Introduction and Literature Review Thesis Chapters, Osei Yaw Akoto, Joseph Benjamin A. Afful

(see Zarei\&Mansoori, 2011). Due to this model's academic discourse-orientedness, it has been labelled 'a model of metadiscourse in academic text' (Zarei \&Mansoori, 2011: 45).

Further, Hyland's model of metadiscourse is preferred to the others because it is the most widely used model in the literature on metadiscourse. The widespread preference of this model can be attributed to its multidisciplinary coverage, as underscored by Afros (2007) that 'it encompasses concepts and methods from diverse knowledge...' (p. 13). Lischinsky (2008: 128) also testifies that one strength of Hyland's model over all others is that it has been profitably used to explore other knowledge-creating and -establishing genres, such as textbooks, scientific letters and research articles'.

\section{Method}

\subsection{Data Sets and Procedure of Analysis}

The data used for the study were Master of Philosophy (MPhil) theses submitted to the Department of English, University of Cape Coast. These theses satisfied both institutional and disciplinary requirements as they had been passed by disciplinary gatekeepers (external and internal assessors, and supervisors) and the School of Graduate Studies. They were available in non-electronic format in the libraries of the department. The Introduction and the Literature Reviews Chapters were photocopied and typed, after which they were proofread.

A worksheet based on Hyland's (2005) metadiscourse model was designed to provide guidance in identifying the metadiscourse markers. We manually coded the texts by identifying metadiscourse features based on Hyland's functional metadiscourse model. The use of the functional approach to metadiscourse study is informed by the fact that a linguistic resource, depending on the context, can function as metadiscoursal or non-metadiscoursal element (Hyland, 2005; Ädel, 2005, 2006; Burneikaitè, 2008). Like Ädel (2006), this paper did not focus on error analysis but rather the use of linguistic resources for metadiscoursal functions.

In a qualitative study, 'the personal-self becomes inseparable from the researcher-self' (Creswell, 2003: 182) and more particularly, studying a fuzzy phenomenon such as metadiscourse where the subjective judgement of the analyst is inevitable (Ädel, 2006). Thus, to reduce this subjectivity which is inevitably characteristic of linguistic analysis (Akoto, 2019), and also given that 'there are no simple linguistic criteria for identifying metadiscourse' (Tse \& Hyland, 2006:770), we employed two inter-coders who independently analysed portion of the texts.

The present study adopted Hyland's functional metadiscourse analytical framework since metadiscourse studies begin with functional analyses of texts (Hyland, 2004; Tse \& Hyland, 2006). Besides, the functional analysis of metadiscourse gives greater comprehensibility and distinction to the various metadiscourse features (Akoto, 2020; Heng \& Tan, 2010). The context-sensitive and functionally-oriented model of metadiscourse by Hyland (2005) helped us to resolve the problems of fuzziness, multifunctionality, clustering and double use (Hyland, 2004, 2005; Blagojevic, 2004; Burneikaitè, 2008, 2009). Again, the functional analysis of metadiscourse helped in differentiating 'actual' metadiscourse resources from pseudometadiscoursal elements which performed propositional rather than metadiscoursal functions. In the discussion section, metadiscursive items are provided under each subcategory, and these are bolded and underlined to make them visible to readers.

We identified and categorized the metadiscourse markers into interactive and interactional categories, and then into their various subcategories. We read the texts twice (two weeks interval) to ensure that every metadiscourse element had been examined. Finally, 
the texts were normalized at 10, 000 running words in order to "control length variation and also to allow comparison across corpora of unequal size" (Khedri, Heng \& Ebrahimi, 2013: 325). To ascertain whether the observed differences in the frequencies of metadiscourse markers across the two Chapters were statistically significant, we used the log-likelihood (LL) calculator (freely available at http://ucrel.lancs.ac.uk/llwizard.html), with a statistical significance threshold at 95th percentile; $5 \%$ level; $p<0.05$; critical value $=3.84$. This implies that any LL value below and avoid 3.84 was respectively considered not significant and significant (statistically).

We calculated for the average metadiscourse per page and metadiscourse density. We arrived at metadiscourse per page by dividing the total number of metadiscourse items by the number of pages. Furthermore, we calculated for metadiscourse density to find out how dense the chapters are in terms of metadiscourse use. Metadiscourse density describes the percentage of metadiscourse items in the overall words in any given text. The formula used in computing the metadiscourse density was:

Total No. of MD $\times 100$

Total No. Words

It should, however, be noted that metadiscourse density (MD) does not show how wellwritten a text is (Hyland, 2010). It rather shows the level of interpersonality and interactivity in a text, although Cheng and Steffensen (1996) have established a positive correlation between metadiscourse use and quality writing.

Table 1:

Basic quantitative details on English Introduction and LR Chapters

\begin{tabular}{lllll}
\hline Chapters & No. of words & RF & NF & Metadiscourse Density \\
\hline Introduction & 50,000 & 5,492 & 109.8 & 10.98 \\
LR & 100,500 & 13,261 & 132.0 & 13.20 \\
\hline
\end{tabular}

Table 1 shows that the metadiscourse densities in the two sections are 10.9 for Introduction and 13.20 for LR. Metadiscourse density reveals that the LR Chapter has a greater number of metadiscourse items than the Introduction Chapter. Most importantly, the normed frequency (NF) showed that LR section used more metadiscourse markers than the Introduction section. The log-likelihood statistical test affirms that the observed difference is indeed statistically significant, as the LL value is 174.81 as against the statistical cut-off point of LL 3. 84. Perhaps, the rigorous evaluation required in the LR resulting in the review of nonresearch literature and empirical literature, and discussion of the theoretical and conceptual frameworks (Bitchener, 2009; Yoon \& Römer, 2020) and how they inform the present work account for this. This probably necessitated LR's use of more metadiscourse items to organize the text, guide the reader to ease understanding of the content and more importantly to shape arguments to the needs and expectations of the readers (Hyland, 2010; Gezegin \& Melike, 2020).

The frequency counts in Tables 2 and 3 reveal the crucial role of metadiscourse in English Language Introduction Chapter (ELIC) and English Language Literature Review Chapter (ELLRC). They indicate that English thesis writers regard writing as a social engagement, as contended by Hyland (2004, 2005). Tables 2 and 3 further display the dissimilarities that exist between ELIC and ELLRC in terms of the use of metadiscoursal devices. Interestingly, ELLRC uses more interactive devices (NF 64.0 as against ELIC's NF 56.5), and interactional devices (NF 
68.0 as against ELIC NF 53.4). This finding corroborates Chen's (2011) assertion that "the literature review...is the place where metadiscourse is frequently employed" (p. 94). The predominance of interactional metadiscourse in the LR underlines the writers' efforts to establish socio-rhetorically accepted relationship to their argument and readers in order to persuasively deal with both the non-empirical and empirical literature available in the field of study (Tse \& Hyland, 2006; Gezegin \& Melike, 2020).

Again, the more frequent use of interactional devices in the LR is quite justified, given that it is a persuasive text type (Abdi, 2002) and as Abdi (2002) maintained such texts are mostly interactional metadiscourse-laden. It is also not surprising that interactive features are dominant in the LR as it aims at managing ideational information to explicitly establish the writer's preferred interpretations (Hyland, 2004) and also negotiate entry into the knowledge bank in the field of study (Afful, 2010). It is important to note that the observed differences between the Chapters regarding both interactive and interactional devices are both statistically significant. As shown in Table 4, the log-likelihood (LL) values for interactive and interactional subcategories are 31.00 and 116.17 respectively. Indeed, the LL values are higher than the significance threshold (i.e. 3.84). The markedstatistical significant difference corroborates the assertion that the rhetorical conventions, communicative functions and generic constraints of the two Chapters significantly influence the use of metadiscourse devices (Akoto, 2019, 2020). In the next ensuing two subsections, we discuss the differences between ELIC and ELLRC regarding interactive and interactional subcategories.

\section{Results and Discussion}

\subsection{Variation in the use of Interactive devices across ELIC and ELLRC}

We adopted the concept 'scale of preference', or rank order (Cherk, 2016) which assumes that metadiscourse subcategories are scalable, to show the arrangement of metadiscourse subcategories in their order of importance (Cherk, 2016). The rank of a metadiscourse subcategory determines its importance, as compared with other subcategories. Simply put, the more important a subcategory is, the higher its normed frequency (NF). The scale of preference, raw frequencies (RFs), normed frequencies (NFs), percentages (\%) and rankings of interactive subcategories are shown in Table 2.

Table 2:

Statistical details on Interactive metadiscourse in ELIC and ELRC

\begin{tabular}{llllllllll}
\hline Category & $\begin{array}{l}\text { Introduction } \\
\text { RF }\end{array}$ & NF & $\%$ & Ranking & RF & NF & $\%$ & Ranking \\
\hline Transitions & 830 & 16.6 & 15.11 & $1^{\text {st }}$ & 1927 & 19.2 & 14.53 & $1^{\text {st }}$ \\
\hline $\begin{array}{l}\text { Code } \\
\text { Glosses }\end{array}$ & 761 & 15.2 & 13.86 & $2^{\text {nd }}$ & 1695 & 16.9 & 12.78 & $2^{\text {nd }}$ \\
\hline Evidentials & 443 & 8.9 & 8.07 & $3^{\text {rd }}$ & 1648 & 16.4 & 12.43 & $3^{\text {rd }}$ \\
\hline $\begin{array}{l}\text { Endophoric } \\
\text { Markers }\end{array}$ & 436 & 8.7 & 7.94 & $4^{\text {th }}$ & 567 & 5.6 & 4.28 & $5^{\text {th }}$ \\
\hline $\begin{array}{l}\text { Frame } \\
\text { Markers }\end{array}$ & 353 & 7.1 & 6.43 & $5^{\text {th }}$ & 591 & 5.9 & 4.46 & $4^{\text {th }}$ \\
\hline Total & 2823 & 56.5 & 51.41 & & 6428 & 64.0 & 48.48 & \\
\hline
\end{tabular}

Table 2 shows the scales of preference of interactive metadiscourse in ELIC and ELLRC. We observe similarities between the two chapters. The Introduction Chapter has the following scale of preference: transitions, code glosses, evidentials, endophoric markers, and 
frame markers while the LR chapterfavoured transitions, code glosses, evidentials, frame markers and endophoric markers, in that order. The two respective scales of preference for interactive devices clearly show that both ELIC and ELLRC prefer greater use of transitions, followed by code glosses and then evidentials in that order more than the remaining interactive subcategories. The high preference for transitions in both Chapters show how both English Language thesis writers place high premium on coherent and logical arguments to ensure that readers are engaged in the discourse to acknowledge the preferred interpretations of the writers (Hyland, 2005). The finding is consistent with some previous studies (Akoto, 2019, 2020; Zahra, Roya \& Shahla, 2015).

We note that the similarities regarding ranking of the interactive subcategories outweigh the dissimilarities. Apart from endophorics and frame markers which interchanged positions, all the others maintain a common preference order across both chapters.

Notwithstanding the similarities, there exist quantitative differences across all the metadiscoursal devices in all the interactive subcategories.

The LR Chapter (LRC) employed more transitions (19.2 as against 16.6), and it suggests that in the LR, writers more often logically and coherently organize their arguments to express their preferred interpretation than they do in the Introduction. This is probably due to the fact that it is the chapter that justifies the study's essence (Samraj, 2008) and therefore requires more transitions to weave a researcher's thoughts together. It is shown in Table 3 that the observed difference in transition use between the two Chapters is statistically significant at LL 12.28 , as against the statistical cut-off point of 3.84 .

Table 3:

Log-likelihood values of interactive subcategories across ELIC and ELLR

\begin{tabular}{lll}
\hline Metadiscourse Subcategories & Log-likelihood Value & Significance Status \\
\hline Interactive Subcategories & 31.00 & Significant \\
Transitions & 12.28 & Significant \\
Code Glosses & 5.61 & Significant \\
Evidentials & 147.63 & Significant \\
Endophorics Markers & 45.51 & Significant \\
Frame Markers & 7.26 & Significant \\
\hline
\end{tabular}

Here are examples of transitions use in ELIC and ELRC:

The present study is focused on code choice and since the question of choice applies more to the spoken than the written variety of communication, the research is limited to the spoken medium. (ELIC 0001)

The researchers fail to acknowledge current views that any language system is extremely complex, that many aspect of grammar have never been described and consequently been taught,... (ELLRC 0001)

From the above examples we see how transitions are used in ELIC and ELLRC. The logical and coherent linking of the arguments are probably done in LR, slightly more than in the Introduction to also motivate the readers (Farrokhi \& Ashrafi, 2009), and to sustain their interest to follow the writers' flow of thought into the proceeding chapters.

The next interactive subcategory is code glosses, which are used to offer explanations to some ideational messages in discourse, as shown in extracts ELIC 0002 and ELLRC 0002. 
Variations in Metadiscourse Use in English Language Introduction and Literature Review Thesis Chapters, Osei Yaw Akoto, Joseph Benjamin A. Afful

This means that when two or more individuals communicate with each other in speaking, for example, we can name the system of communication that they employ a code. (ELIC 0002)

This comprises four major variables: intelligence, language aptitude, motivation and situational anxiety. (ELLRC 0002)

Table 2 indicates ELLRC used16.9 as against15.2 in ELIC. This observed difference is significant (statistically) with LL value of 12.78.It is surprising to find that LR employed more code glosses than Introduction, given that the Introduction seeks among other things to contextualize the study by explaining concepts that underpin the study (Afful, 2010; Bitchener, 2009; Samraj, 2008). It was therefore not surprising to find a rhetorical unity Definition of Terms in the Introduction Chapter in all the theses included in the corpus. Bitchener (2009) maintains that all Introduction defines 'specialized vocabulary' (p. 56) in the study to ease readers' comprehension in the successive chapters (Camiciottoli, 2003).

Evidentials reveal the source of textual information outside the evolving text (see Tse and Hyland, 2006; Hyland, 2005), as shown in the corpus evidence ELIC 0003 and ELLRC 0003.

According to Wardhagh and Crystal the concept of code does not refer to only a variety of language, whole languages are also codes. (ELIC 0003)

Thirdly, the chapter looked at literature on conversation as studied by scholars like Kramer (1931), Edelsky (1931), Goffman (1957) and Greenwood (1989). (ELLRC 0003)

Table 2 indicates that LR (16.4) exceedingly used more evidentials than Introduction (8.9). This finding is not surprising since the LR is said to be characterized by greater use of evidentials (Afful, 2010; Bitchener, 2009; Chen, 2011) as authors display their knowledge of their field of knowledge through the citations they use. In the master's thesis, critique of other works to show the uniqueness of one's study is the role of the LR. Bitchener (2009) argues that extensive citation is not the norm in the Introduction but in the LR. This marked statistical difference between the two Chapters suggests that English Language thesis writers display their acquaintance with the existing literature in their field more in the LR than in the Introduction. The preponderance of evidentials in the LR than in the Introduction buttresses Ädel's (2006: 188) hypothesis that 'some types of metadiscourse tend to occur at specific points in texts'. Now the subsequent section concentrates on differences in interactional items across the two engaged sections in the English master's theses.

Now let us turn to endophorics and frame markers, where the Introduction Chapter outweighs the LR Chapter. Regarding endophorics, Introduction employed 8.7 as against LR's 5.6 in 10, 000 running words.

This chapter provides an insight into the theme of the current research. (ELIC 0004)

The preceding discussion has been an overview of the four theories. (ELLRC 0004)

As text-organising devices (see Burneikaitè, 2009; Hyland, 2005), as demonstrated in ELIC 0004 and ELLRC 0004, endophorics signal writer's attempt to manage the structure of the 
ongoing discourse. It was observed that the Introduction Chapter deployed more rhetorical sections than the LR Chapter. Thus, Introduction requires more use of endophorics to weave the preceding and proceeding sections together in order to provide a well-interwoven text.

Moreover, frame markers were also deployed more frequently in the Introduction section (7.1) than in the LR (5.9) per 10, 000 tokens, and this difference is statistically significant with LL value of 7.26 at 3.84, the statistical cut-off point. Hyland (2005) outlined four main functions of frame markers: sequencing, stage labeling, topic shifting and goal announcing. The underuse or overuse of frame markers therefore has implication for how writers guide their readers through texts. Hence, frame markers have some bearing on the readability on comprehensiveness of a text. Camiciottoli (2003), therefore, found that the text which contained more frame markers was more comprehensible than the one that contained less. Based on this, we can remark that the Introduction appears more comprehensible than the Literature. This is probably so because the Introduction is the 'entry chapter' where the writer needs to 'arrest' the readers' interest (Afful, 2010). See frame markers use in ELIC and ELLRC.

However, for the purpose of this research, no distinction is made between one Ghanaian who speaks only one language (the mother tongue) and another who speaks more than one (the mother tongue and other Ghanaian languages) as far as the learning of English is concerned. (ELIC 0005)

The present study focuses on the last of the three because, according to Petric (2005), authorial presence is constructed, among others, by relating to others. (ELLRC 0005)

The foregoing evidence makes clear one revelation - that writers more frequently refer to the other parts of their works to clarify additional materials to the readers (Hyland, 2006) than they do in the LR. The finding is not surprising because previewing of thesis organization, and goal stating are parts the function of the Introduction Chapter (Samraj, 2008). More so, the frame markers have shown that more often in the Introduction, than in the LR, writers use language more reflexively to refer to text boundaries to sequence propositional information, to label text stages, to declare discourse goals, and to indicate topic shifts (Hyland, 2004, 2005). This is quite justifiable because ELIC has more rhetorical sections such as 'background to the study', statement of the problem', hypotheses/research questions...', than in the LR, which mostly capture review of empirical studies and the discussion of conceptual and theoretical frameworks.

\subsection{Variation in the use of Interactional devices across ELIC and ELLRC}

Table 4 displays, among other things, the rank, raw frequencies (RFs), and normed frequencies of interactional subcategories across ELIC and ELLRC. It is interestingly to note that the two chapters have the same scale of preference for interactional subcategories: hedges, boosters, attitude markers, engagement markers, continuants, and self mentions. This shared pattern suggests that thesis-parts are not completely dissimilar. 
Variations in Metadiscourse Use in English Language Introduction and Literature Review Thesis Chapters, Osei Yaw Akoto, Joseph Benjamin A. Afful

Table 4:

Frequency of Interactional Metadiscourse in ELIC and ELRC

\begin{tabular}{lllllllll}
\hline Category & $\begin{array}{l}\text { Introduction } \\
\text { RF }\end{array}$ & $\mathbf{N F}$ & $\mathbf{( \% )}$ & Ranking & $\mathbf{R F}$ & $\mathbf{N F}$ & $\mathbf{( \% )}$ & Ranking \\
\hline Hedges & 1206 & 24.1 & 21.96 & $1^{\text {st }}$ & 2652 & 26.4 & 20.0 & $1^{\text {st }}$ \\
\hline Boosters & 685 & 13.7 & 12.47 & $2^{\text {nd }}$ & 1830 & 18.2 & 13.80 & $2^{\text {nd }}$ \\
\hline $\begin{array}{l}\text { Attitude } \\
\text { Markers }\end{array}$ & 523 & 10.5 & 9.52 & $3^{\text {rd }}$ & 1825 & 18.1 & 13.76 & $3^{\text {rd }}$ \\
\hline $\begin{array}{l}\text { Engagement } \\
\text { Markers }\end{array}$ & 183 & 3.7 & 3.33 & $4^{\text {th }}$ & 384 & 3.8 & 2.90 & $4^{\text {th }}$ \\
\hline Continuants & 40 & 0.8 & 0.73 & $5^{\text {th }}$ & 102 & 1.0 & 0.77 & $5^{\text {th }}$ \\
\hline $\begin{array}{l}\text { Self } \\
\text { Mentions }\end{array}$ & 32 & 0.6 & 0.58 & $6^{\text {th }}$ & 40 & 0.4 & 0.30 & $6^{\text {th }}$ \\
\hline Total & 2669 & 53.4 & 48.59 & & 6833 & 68.0 & 51.53 & \\
\hline
\end{tabular}

The highest preference for hedges and the lowest preference for self mentions across the two Chapters confirm some studies on interactional devices in master's thesis (e.g. Akoto, 2019, 2020; Hyland, 1998 2004, 2010). The first rank of hedges arguably confirms the centrality of hedges in academic writing (Hyland, 1998; Musa, 2014a, b) and master's students' reluctance to explicitly establish their authorial presence in their works (Hyland, 2004, 2010).

The NFs in Table 4 show that the LR uses more hedges, boosters, attitude markers, engagement markers and continuants than the Introduction Chapter. Self mentions is the only interactional subcategories where Introduction employed more than the LR. In the ensuing paragraphs we discussed these findings into details.

It shown in Table 4 that hedges are more frequent in ELLRC (26.4) than in the ELIC (24.1). The results of the log-likelihood statistical test (LL 6.77) shown in Table 5 also indicate that the difference observed is statistically significant.

Table 5:

Log-likelihood values on interactional subcategories across ELIC and ELLR

\begin{tabular}{lll}
\hline Metadiscourse Subcategories & Log-likelihood Value & Significance Status \\
\hline Interactional metadiscourse & 116.17 & Significant \\
Hedges & 6.77 & Significant \\
Boosters & 42.03 & Significant \\
Attitude Markers & 135.96 & Significant \\
Engagement Markers & 0.23 & Not Significant \\
Continuants & 1.68 & Not Significant \\
Self Mentions & 3.91 & Significant \\
\hline
\end{tabular}

This affirms the view that the varied purposes and positions of the two Chapters strongly influence their use of hedges. LR's more frequent use of hedges reflects its greater respect that writers accord their readers in the presentation of their points of view in conceptual, theoretical and empirical matters in the master's thesis. The extracts below indicate examples of hedges in Introduction and LR.

For instance in most work places in Ghana a subordinate is likely to initiate an informal discourse with a superior in English. (ELIC 0006) 
Bloom and Lahey's (1978) work also does not entirely support the behaviourist theory of language learning. (ELLRC 0006)

We note that writers show deference to readers and scholars in their chosen field in the LR in order to establish a niche for their works. In the LR, writers establish a virtual community which comprises themselves, others writers and readers. They require more use of hedges to withhold their commitments to their propositions given that there exists multiplicity of perspectives from the readers and the scholars in the area. But usually, the introduction seeks to contextualize the study, writers require less use of hedges to make them their claims.

Furthermore, writers use more engagement markers in the LR than in the Introduction. The normed frequencies in Table 4 reveal this and the $L L$ value in Table 4 support that the differences between the Chapters with respect to the use of engagement markers is statistically significant. The difference implies that writers involve their readers in the LR more than they do in the Introduction. Examples of engagement markers in both thesis-parts genres are provided below:

\section{How do educated Ghanaians generally make refusals in English? (ELIC} 0007)

It is imperative to examine in some detail how children acquire their first language in order to project its usefulness as the language of instruction in the early years of formal education. (ELLRC 0007)

The present finding is justifiable given that in the Introduction writers generally engage with their readers only to share the studies with. However, in the LR, writers do not only communicate with readers, but other scholars as well. Ädel's (2006) triangle becomes appropriate in this regard, where there exists a triangular relationship among the three key discourse participants in the virtual textual community. Thus, the socialization in the LR is more pronounced in the LR, given its role in the thesis genre (Bithener, 2009).

Similarly, postgraduates in English establish their authorial presence in the Introduction more than they do in the LR. Table 3 indicates that the frequencies in Introduction and LR are 0.6 and 0.4 respectively per 10,000 running words. Self mentions reveal the authorial identity and authority of writers, Hyland (2001) contends. The figures, therefore, suggest that writers reveal themselves more frequently as discourse participants in the Introduction more than in the LR. See the examples below:

It is this need that leads me to the present enquiry. (ELIC 0008)

Then I have explained $\underline{m} \mathbf{y}$ research design and why it is different from the researches cited and discussed. (ELLRC 0008)

Ädel (2006) argues that persuasive texts, like the LR, require much of the presence of the writer to help enforce his views to enable his readers 'internalise' them (Ädel, 2006:88) but this study indicates otherwise. Most likely the position of the Introduction Chapter as the first chapter contributes to the frequent use of self mentions. Comparatively, it allows the writers to advertise, market themselves as legitimate discourse participants who are capable to lead the readers in the 'textual tourism' in the thesis through to the last chapter. It is also important to note that the observed difference between the two Chapters with respect to the use of self mentions is statistically significant, since the LL (i.e. 3.91), as shown in Table 4, is more than the statistical benchmark, which is 3.84 . 
Variations in Metadiscourse Use in English Language Introduction and Literature Review Thesis Chapters, Osei Yaw Akoto, Joseph Benjamin A. Afful

LR deployed reasonably more boosters than the Introduction, given than per 10, 000 token LR used 18.2 boosters while Introduction used 13.7. It is shown in Table 4 that the LL values for the Chapters is 42.03 , indicating that the difference observed between the two Chapters is significant (statistically). This finding affirms the assertion that rhetorical choices in the Introduction and LR are informed by their rhetorical functions (e.g. Bitchener, 2009). The examples below are evidence of boosters used in the Introduction and the LR.

Basic school children show greater syntactic complexity in their sentence structures as they progress from a lower level to a higher level. (ELIC 0009)

Again, in sentence 2, from Huddleston (1984: p.59) the theme is close tabs and it is obviously not the topic. (ELLRC 0009)

Hyland (2000) argues that boosters are rhetorical strategies adopted to increase the force of propositions made. Thus, writers induce stronger forces in their statements in the LR more frequently than in the Introduction. It is has been argued that the LR Chapter is the place for readers to synthesize the views of others in order to critically evaluate them to make a case of their present study (Bitchener, 2009; Fitt, Walker, \& Leary, 2009). Consequently, the frequent use of boosters in this Chapter than in the Introduction that among other things seeks to contextualize the study (Akoto, 2019) is justified.

Next, Table 4 reveals that continuants were more frequent in LR (1.0) than in Introduction (0.8), although the log-likelihood statistical significance test shows that the observed difference is not statistically significant (see Table 5). However, the more frequent use of continuants in the LR challenges Woodward-Kron's (2002: 507) view on text book that readers are 'moved from commonsense world of every day experience into the "uncommonsense'" world as chapters unfold. It must be noted that as shown in ELIC 0010 and ELLRC 0010, the underlined expressions rhetorically engage readers as members of the discourse community, familiar with the disciplinary epistemology. The metadiscoursal roles of these rhetorical choices troubles the view that such expressions are markers of imprecision (Lin, 2013; Alkhatnai, 2017), or limitations. Interestingly, continuants are implied in such concepts as general extenders (Overstreet \& Yule, 2002; Parveresh \& Dabghi, 2013), extension particles (De Cock, 2004) or markers of shared knowledge and experience (Lin, 2013), and epistemic vague stance markers (Biber, 1995 as cited in Alkhatnai, 2017).

Every Ghanaian child born and living in Ghana has a first language -Akan, Ewe, Ga, Nzema and so on. (ELIC 0010)

Downing and Locke's (1992) work on syntax deals among other things, with the syntactic characteristics of clauses and phrases. (ELLRC 0010)

This implies that English postgraduate, comparatively assume, what may be called 'Literature Review knowledge' as 'core disciplinary knowledge' than in the Introduction. Even though English postgraduate thesis writers engage their readers more in the Introduction, they require less of their (readers') input in this section, as continuants implies "assumed or shared knowledge and mark in-group membership" (O'Keeffe, McCarthy \& Carter, 2007: 177). Lin $(2012,2013)$ asserts that continuants indicate writer's sensitivity of their readers who invariably are knowledge community members. The relative difference suggests that LR acknowledges readers as being familiar with the literature on concepts and theories employed 
in such studies. Hence, readers are given a space (0.2) more in the LR than in the Introduction to contribute to the knowledge-making enterprise.

Turning to attitude markers, LR utilized as high as 18.2 as against 10.5 in Introduction, per 10, 000 running words. Attitude markers indicate the overflow of the writer's affective or emotive use of language, as indicated in ELIC 0011 and ELLRC 0011. Specifically, they explicitly manifest writer's surprise, (dis)satisfaction, frustration, etc. to propositions. Our results, therefore, underscore that writers comparatively display their feelings about their ideational materials in the LR than in the Introduction.

It is therefore necessary that we get to know how people make refusals so that we know how to react or approach them in the event of a refusal from them. (ELIC 0011)

Positive regard for the culture associated with the language also helps. (ELLRC 0011)

The present finding contrasts Crismore and Farnsmore's (1989) study where they found chapter one of their corpora to have contained more attitude markers than chapter two. The contrast is quite justifiable since Crismore and Farnsworth study was on textbook whereby chapter two, unlike in the thesis genre, does not necessarily involve critique of previous works. Hence, our present finding appears quite undisputed. Since the LR resorts to previous works, there is more likelihood that the writer would display his/her pleasure or otherwise to the methodology, theories, concepts, analytical frameworks and findings of such studies.

\section{Conclusion}

It is established that metadiscourse use in theses is chapter-specific (Akoto, 2019, 2020; Burneikaite, 2008, 2009a, b, c). The present study sought to further investigate this conclusion by focusing on the Introduction and Literature Review (LR) Chapters in master's thesis from an English-medium university in Ghana. Guided by Hyland's (2005) model of metadiscourse, we manually searched the data and identified all metadiscursive resources. After this, the authors profiled the frequencies of all the interactive and interactional subcategories and normed them per 10, 000 words. This was followed by discussions of the findings.

We found that the Introduction and LR share some differences and similarities. Regarding, the ranking of metadiscoursal items, it was found that the two chapters give prominence to transitions, and hedges which are respectively interactive and interactional subcategories. On the other hand, it was realized that there are quantitative difference in all the five interactive subcategories and the six (with new additions) interactional subcategories. The log-likelihood statistical significance test indicates that except engagements and continuants, the observed differences in all the others were statistically significant, indicating that the positioning and rhetorical functions of the two Chapters influence the use of such metadiscoursal subcategories.

The above findings have implications for the theory of metadiscourse, and English for Academic Purposes. It has been argued that an empirical study, which is theory-oriented should generate, modify or verify a theory. Interestingly, this study has discovered some elements which are metadiscoursal but hitherto had been denied metadiscursivity. These elements, tagged continuants, create dialogic space in text to allow readers to be active participants in knowledge construction in academic text. Examples of these include 'and so 
Variations in Metadiscourse Use in English Language Introduction and Literature Review Thesis Chapters, Osei Yaw Akoto, Joseph Benjamin A. Afful

on', 'etc' and '...'. Hence, the present study has modified Hyland' (2005) model by introducing another sub-division to interactional metadiscourse.

Finally, it has implication for further studies on thesis chapters across cultures and more disciplines. We agree with Burneikaitè (2008) that 'further analysis of a larger corpus of data is necessary to make generalizations in a more confident manner" (p. 44) regarding the variation in metadiscourse use in Introduction and Literature Review Chapters in master's theses.

\section{References}

Abdi, R. (2002). Interpersonal metadiscourse: An indicator of interaction and identity. Discourse Studies. 4: 139-145.

Abdi, R., Rizi, M. T. \& Tavakoli, M. (2009). The cooperative principle in discourse communities and genres: A framework for the use of metadiscourse. Journal of Pragmatics. 42, 1669-1679.

Abdollahzadeh, E. (2011). Hedging in postgraduate student theses: A cross-cultural corpus study. International Conference on Language, Literature and Linguistics. 26, 581-586.

Ädel, A. (2005). On the boundary between evaluation and metadiscourse. In TogniniBonnelli,E. and Camiciotti, G., D., L. (eds.). Strategies in academic discourse (Studies in Corpus Linguistics). 153-162 Amsterdam/PhilÄdelphia: John Benjamins.

Ädel, A. (2006). Metadiscourse in L1 and L2English. PhilÄdelphia: John Benjamins.

Ädel, A. (2010). Just to give you kind of a map of where we are going: Ataxonomy of metadiscourse in spoken and written academic English. Nordic Journal of English Studies, 9(2), 69-97.

Afful, J. B. A. (2010). The rhetoric of undergraduate student writing in a Ghanaian university: A cross-disciplinary study. Saarbrucken: Lambert Academic Publishing.

Afros, E. (2007). Promotional (meta) discourse in research articles in Language and Literary Studies. Unpublished Masters' Thesis. University of Waterloo, Waterloo, Ontario.

Aguilar, M. (2008). Metadiscourse in academic speech: A relevance theoretic approach. Berlin: Peter Lang.

Akoto, O. Y. (2019). Metadiscourse use in English Language and Sociology master's thesesliterature review chapters. ESP World, 57 (21), 1-31

Akoto, O. Y. (2020). Metadiscourse within a discipline: A study of introduction and literaturereview chapters of sociology masters' theses. Indonesian Journal of AppliedLinguistics, 10(2), 471-480.

Alkhatmai, M. (2017). Vague language and its social role. Theory and Practice in Language Studies. 7(2), 122-127.

Beauvais, P. J. (1989). A speech act theory of metadiscourse. Written communication, 6(1), 11 30.

Becher, T. (1989). Academic tribes and territories: intellectual enquiry and the cultures ofdisciplines. Milton Keynes and Bristol, USA. The Society for research into Higher Educational/Open University Press

Biglan, A. (1973). Relationships between subject matter characteristics and the structure andoutput of university departments. Journal of Applied Psychology 57(3), 207-213.

Bitchener, J. (2009). Writing an applied linguistics thesis or dissertation: A guide to presenting empirical research. Macmillan International Higher Education. 
Blagojevic, S. (2004). Metadiscourse in academic prose: A contrastive study of academic articles written in English by English and Norwegian native speakers. Studies about Languages. 5, 60-67.

Burneikaitè, N. (2008). Metadiscourse in Linguistics masters' theses in English L1 and L2. Kalbotyra. 59(3), 38-47.

Burneikaitè, N. (2009a). Endophoric markers in Linguistics master's theses in English L1 \&L2. Man \& the Word/Zmogusirzodis, 11(3), 11-16.

Burneikaitè, N. (2009b). Evaluative metadiscourse in linguistics master's theses in English L1 \&L2. Language in Different Contexts. KalbairKontekstai, 3(1), 87-95.

Burneikaite, N. (2009c). Metadiscoursal connectors in linguistics MA theses in English L1 \&L2. Kalbotyra, 61(61), 36-50.

Camiciottoli, B. C. (2003). Metadiscourse and ESP reading comprehension: An exploratory study. Reading in a Foreign Language, 15(1), 28.

Can, C. \& Yuvayapan, F. (2018). Stance-taking through metadiscourse in doctoral dissertations. International Journal of Languages' Education and Teaching. 6(1), 128-142.

Chen, M. (2011). Functions of perspectival metadiscourse in reporting in literature reviews. Journal of Cambridge Studies. 93-106.

Cheng, X. \& Steffensen, M. S. (1996). Metadiscourse: A technique for improving student writing. Research in the Teaching of English. 30 (2):149-181.

Cherk, L. M. (2016). Characterizing the Metadiscourse of the Pure Math PhD Thesis. NUS CELC5 ${ }^{\text {th }}$ Symposium Proceedings, 124-134

Creswell, J. W. (2003). Research design: Qualitative, quantitative and mixed approaches $\left(2^{\text {nd }}\right.$ ed.). California: Sage Publications Inc.

Crismore, A. \& Farnsworth, R. (1989). Mr. Darwin and his readers: Exploring interpersonal metadiscourse as a dimension of ethos. Rhetoric Review. 8(1), 91-112.

Crismore, A. (1984). The rhetoric of textbooks: Metadiscourse. Journal of Curriculum Studies. 16, 279-296.

Crismore, A., Markkanen, R. \& Steffensen, M. S. (1993). Metadiscourse in persuasive writing: A study of texts written by American and Finnish university students. Written Communication. 10 (1), 39-71.

De Cock, S. (2004). Preferred sequences of words in NS and NNS speech. Belgium Journal of English and Literatures (BELL), New Series 2, 225-246.

Duruk, E. (2017). Analysis of metadiscourse markers in academic written discourse produced by Turkish researchers. Journal of Language and Linguistic Studies. 13(1), 01-09.

Fitt, M. H., Walker, A. E. \& Leary, H. M. (2009). Assessing the quality of doctoral dissertation literature review in Instructional Technology. Paper presented at the Annual Meeting of the American Educational Research Association, San Diego, CA.

Gee, J.P. (1999). An Introduction to discourse analysis: Theory and method. London: Routledge.

Genegin, B. B., \& Melike, B. A. S. (2020). Metadiscourse in academic writing: A comparison ofresearch articles and book reviews. Eurasian Journal of Applied Linguistics, 6(1), 45 62.

Haufiku, N. K. T. \& Kangira, J. (2018). An exploration of hedging and boosting devices used in academic discourse focusing on English theses at the University of Namibia. Studies in English Language Teaching. 6(1), 1-11. 
Variations in Metadiscourse Use in English Language Introduction and Literature Review Thesis Chapters, Osei Yaw Akoto, Joseph Benjamin A. Afful

Heng, C.S. \& Tan, H. (2010). Extracting and comparing the intricacies of metadiscourse of two written persuasive corpora. International Journal of Education and Development Using Information and Communication Technology (IJEDICT). 6 (3), 124-146.

Hyland, K. (1998). Boosting, hedging and the negotiation of academic knowledge. TEXT. 18(3), 349-382.

Hyland, K. (2000). Disciplinary discourses: Social interactions in academic writing. London: Longman.

Hyland, K. (2001). Humble servants of the discipline? Self mention in research articles. English for Specific Purposes. 20, 207-226.

Hyland, K. (2004). Disciplinary interactions: Metadiscourse in L2 postgraduate writing. Journal of Second Language Writing. 13, 133-151.

Hyland, K. (2005). Metadiscourse: Exploring interaction in writing. New York: Continuum.

Hyland, K. (2009). Academic discourse: English in a global context. London: Continuum.

Hyland, K. (2010). Metadiscourse: Mapping interactions in academic writing. Nordic Journal of English Studies. 9(2), 125-143.

Hyland, K. (2017). Metadiscourse: What is it and where is it going?. Journal of pragmatics, 113, 16-29.Hyland, K.,

Jin, X. \& Shang, Y. (2016). Analyzing metadiscourse in the English abstracts of BA theses. Journal of Language Teaching and Research. 7(1), 210-215.

Khedri, M., Heng, C. S. \& Ebrahimi, S. F. (2013). An exploration of interactive metadiscourse markers in academic research article abstracts in two disciplines. Discourse Studies. 15(3), 319-333.

Kumpf, E. P. (2000). Visual metadiscourse: Designing the considerate text. Technical Communication Quarterly, 9(4), 401-424.

Lin, Y. L. (2012). Mind the gap! Textbook conversation vs. authentic intercultural interaction. In Y. Leung, K. Cheung, W. Dai, C. Hsiao, \& J. Katchen (Eds.), Selected Papers from the $21^{\text {st }}$ International Symposium on English Teaching (pp. 42-54). Taipei: Crane Publishing.

Lin, Y. L. (2013). Vague language and interpersonal communication: An analysis of adolescent intercultural conversation. International Journal of Society, Culture \& Language. 1(2), 69-81.

Lischinsky, A. (2008). The construction of expert knowledge in popular Management literature. Unpublished PhD Dissertation, Universtat Pompeu Fabra.

Musa, A. (2014a). Hedging strategies in English and Chemistry masters' theses in the University of Cape Coast, Ghana. Journal of ELT and Applied Linguistics (JELTAL), 2(3), 53-71.

Musa, A. (2014b). Hedging in academic writing: A pragmatic analysis of English and Chemistry masters' theses in a Ghanaian university. English for Specific Purposes, 42, 1-26.

O'Keeffe, A., McCarthy, M., \& Carter, R. (2007). From corpus to classroom: Language use and language teaching. Cambridge: Cambridge University Press.

Olmos-Lopez, B. (2015). A framework for analysis of authorial identity: Heterogeneity among the undergraduate dissertation chapters. An unpublished doctoral dissertation. Lancaster University.

Overstreet, M., \& Yule, G. (2002). The metapragmatics of and everything. Journal of Pragmatics, 34(6), 785-794.

Samraj, B. (2008). A discourse analysis of master's theses across disciplines with a focus on introductions. Journal of English for Academic Purposes. 7(1): 55-67. 
Tse, P. (2004). Metadiscourse in academic writing: A reappraisal.Applied Linguistics. 25 (2), 156-177.

Tse, P. \& Hyland, K. (2006). 'So what is the problem this book addresses?' Interactions in academic book reviews. Text and Talk. 26 (6):767-790

Vande Kopple, W. (1985). Some exploratory discourse on metadiscourse. College Composition and Communication. 36, 82-93.

Williams, M. (2010). Translating metadiscourse: An explanatory analysis of problems in students' work. Mutatis Mutandis. 3(1), 73-90.

Woodward-Kron, R. (2002). Academic discourses and their discourses of learning: Participants, texts and social practices. In Candling, C. N. (Ed.). Research and practice in professional discourse. 499-523. Hong Kong: City University of Hong Kong Press.

Yoon, H. J., \& Römer, U. (2020). Quantifying disciplinary voices: An automated approach to interactional metadiscourse in successful student writing. Written Communication, 37(2), 208-244.

$\mathrm{Yu}, \mathrm{H}$. (2016). Stance markers in English academic writing in Applied Linguistics: A corpusbased comparison between Korean graduate students' master's theses and published journal articles. Unpublished doctoral dissertation. Seoul National University.

Zahra, R. Z., Roya, B. \& Shahla, S. (2015). Interactive and interactional meta-discourse markers in conclusion sections of English master theses. International Journal of Research Studies in Language Learning. 4(4), 81-92.

Zarei, G. R., \& Mansoori, S. (2011). A contrastive study on metadiscourse elements used in humanities vs. non humanities across Persian and English. English Language Teaching, 4(1), 42-50. 